\title{
Stakeholder involvement through national panels and surveys to address the issues and uncertainties arising in the preparedness and management of the transition phase
}

\author{
M. Montero ${ }^{1, *}$, R. Sala ${ }^{1}$, C. Trueba ${ }^{1}$, B. García-Puerta ${ }^{1}$, B. Abelshausen ${ }^{8}$, J. Bohunova ${ }^{9}$, P. Croüail ${ }^{2}$, \\ V. Durand ${ }^{5}$, T. Duranova ${ }^{9}$, C. Hilliard ${ }^{3}$, M. Maitre ${ }^{2}$, D. Mitrakos ${ }^{4}$, O. Monteiro Gi1 ${ }^{11}$, P. Nunes ${ }^{10}$,

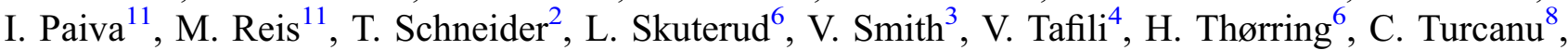 \\ C. Twenhöfel ${ }^{7}$ and E. Van Asselt ${ }^{12}$ \\ ${ }^{1}$ CIEMAT - Centro de Investigaciones Energéticas, Medioambientales y Tecnológicas, Madrid, Spain. \\ ${ }^{2}$ CEPN-Centre d'étude sur l'Évaluation de la Protection dans le domaine Nucléaire, Fontenay-Aux-Roses, France. \\ ${ }^{3}$ EPA - Environmental Protection Agency, Dublin, Ireland. \\ ${ }^{4}$ EEAE-Greek Atomic Energy Commission, Athens, Greece. \\ ${ }^{5}$ IRSN - Institute for Radioprotection and Nuclear Safety, Fontenay-Aux-Roses, France. \\ ${ }^{6}$ DSA - Norwegian Radiation and Nuclear Safety Authority, Østerås, Norway. \\ ${ }^{7}$ RIVM-Rijksinstituut voor Volksgezondheid en Milieu, Bilthoven, the Netherlands. \\ ${ }^{8}$ SCK-CEN-Belgian Nuclear Research Centre, Mol, Belgium. \\ 9 VUJE-VUJE a.s, Trnava, Slovak Republic. \\ 10 APA - Agência Portuguesa do Ambiente, Amadora, Portugal. \\ ${ }^{11}$ IST-C2TN - Instituto Superior Técnico, Centro de Ciências e Tecnologias Nucleares, Lisbon, Portugal. \\ 12 WFSR - Wageningen Food Safety Research, Wageningen, the Netherlands.
}

\begin{abstract}
Under the framework of the CONFIDENCE project, work package 4 was focusing on the transition to long-term recovery, involving stakeholders in decision-making processes. The essential research was performed using a participatory approach, which combined scenario-based stakeholder discussion panels and transnational stakeholder surveys following the Delphi methodology. The objective was to identify and address the issues and uncertainties arising in the preparedness and management of the transition phase and to explore ways to facilitate the incorporation of stakeholders' expertise, points of view and interests in the decision-making processes. The final goal was to build best practices for planning optimal remediation strategies during the transition phase considering stakeholder involvement in the decision-making process. The results obtained from the work undertaken in nine European countries are presented.
\end{abstract}

Keywords: emergency preparedness / transition phase / recovery / decision-making / stakeholder engagement / Delphi survey / CONFIDENCE

\section{Introduction}

Nuclear emergency response plans should include provision for the transition from the emergency exposure situation to an existing exposure situation should be carefully approached (Council Directive 2013/59/EURATOM). This transition phase, also called the "intermediate phase" (Cousins, 2019 ) is a broad and complex phase, where efforts are made to terminate and withdraw the emergency response actions and

\footnotetext{
*Corresponding author: milagros.montero@ciemat.es
}

establish specific plans for the recovery phase, including remediation, to support the resumption of social and economic activity, insofar as possible (de Lhoneux, 2017; IAEA, 2018).

A careful approach to the transition phase is essential to prepare for future management, as the situation changes from an emergency to an existing exposure situation. For this purpose, the plans need to be developed through a process of national dialogue with stakeholder involvement, taking into account the inherent uncertainties in the knowledge of the real consequences of an accident, the strategies to be implemented and the potential socioeconomic impact on the affected population. 
The WP4 of the CONFIDENCE project was devoted to improving the preparedness and response during the transition phase after a nuclear accident, specifically by identifying and trying to reduce the uncertainties in the subsequent management of the long-term exposure situation, while reflecting the requirements of the EU Basic Safety Standards (BSS) (Council Directive 2013/59/EURATOM). Different tools and participatory approaches have been used to facilitate the incorporation and elucidation of the expertise, the points of view and interests of different stakeholders. The final goal was to build best practices for planning optimal remediation strategies for the transition phase considering stakeholder involvement in the decision-making process.

Previous experiences highlighted the importance of nuclear emergency and recovery preparedness and the need to involve all relevant stakeholders (Dubreuil et al., 2010; Liland and Skuterud, 2013; Charron et al., 2016; Liutsko et al., 2019; Lochard et al., 2019). In addition, using scenarios built on realistic assumptions in stakeholder fora is a key mechanism for successful interaction and feedback at all decision levels, and for better post-accident preparedness (Gallego and Montero, 2016).

Adopted as a complementary approach, the "Delphi method" has proven a popular tool for identifying and prioritizing issues in diverse research fields (Gordon, 1994). It is a structured technique for eliciting and combining responses. The stakeholder Delphi approach, contrary to "classical Delphi" can facilitate the interactive participation and consensus building among dissimilar, hierarchical, and possibly antagonistic stakeholder groups. The experts, local authorities and other non-experts stakeholder are included assuming that their knowledge and opinions are valid inputs to research (Bunting, 2010). This technique is particularly appropriate when decision-making is required in a political or emotive environment, or when the decisions affect strong factions with opposing objectives. It is also considered a good tool for giving equal attention to minority viewpoints.

Based on these methodologies, a participatory approach to facilitate stakeholder's involvement and provide valuable input in the process of decision-making has been designed in the following way:

- scenario-based stakeholder discussion panels were organised to test and evaluate the national dialogue process with stakeholders during the transition to recovery. What to do and how to proceed in a generic nuclear accident scenario and how to evaluate the potential consequences of decisions and their impacts on achieving acceptable living conditions, were the focus of the discussions;

- a Delphi study, as a series of structured transnational stakeholder consultation surveys, was carried out in parallel to the panels. The specific aim was to involve a higher and more heterogeneous sample of stakeholder in the assessment of the main issues and uncertainties and to select and prioritise the most relevant criteria. The MultiCriteria Decision Analysis (MCDA) tool developed under the WP6 was used by some national stakeholder panels, which provided a transparent approach for choosing a suitable strategy from a pool of strategies taking into account the different preferences of the involved stakeholders (Müller et al., 2019, 2020).

The methodology, the main results, findings and conclusions are described below.

\section{Methodology}

\subsection{Stakeholder panels}

Nine national stakeholder panels were set up in different European countries: Belgium, Ireland, France, Greece, The Netherlands, Norway, Slovak Republic, Spain and Portugal. Each of them defined their main concerns and issues of interest, the type and role of the potential stakeholders attending and the connection and coordination with other CONFIDENCE stakeholder panels, foreseen in WP5 (Baudé et al., 2019) and WP6 (Duranova et al., 2020a). Tables 1 and 2 show, respectively, for nuclear and non-nuclear countries, the overview of the different panels in terms of emergency phases, scenarios and main goals considered.

The panels had a varied composition, including experts and representatives of stakeholders directly involved in postemergency planning and the management of the transition phase, others affected but not involved in such management and/or others unaffected but interested.

Each participating country conducted a "question-driven" table-top exercise, in one or two sessions, based on representative contamination scenarios situated in the transition phase. Common guidelines based on a structured methodology using decision-oriented scenario-analysis were prepared to help the organisation and discussions of the national panels (Montero et al., 2018). Discussions focussed on an intervention scenario describing the actual and future situation, from a hypothetical accident at a nuclear power plant (NPP) situated in the country or nearby to it. It was based on the contamination pattern monitored after the release was controlled and the contamination was deposited. The different alternative options to address the consequence management and the post-accident recovery planning that might be considered during the transition phase were the focus of the exercise.

Several objectives were pursued:

- to understand the transition phase;

- to follow the timeline and the challenges in the decisionmaking process, including the decisions taken in the early phase of the emergency;

- to identify the critical aspects in the preparedness and response for the recovery;

- to draft an approach to deal with the uncertainties arisen in the transition phase;

- to prepare plans for the subsequent recovery, and;

- to explore how and at what level to engage the stakeholders in the decision-making process.

The results obtained in each national panel were crossanalysed and compiled in a structured grid according to the main issues, criteria and uncertainties identified by the panels (see Durand et al., 2020; Montero et al., 2020).

\subsection{Delphi study}

An adaptation of the original Delphi methodology (Campbell et al., 2000; Tetzlaff et al., 2012) was carried out with the aim of eliciting the perceptions of stakeholder with diverse backgrounds, and to explore consensus regarding the 
Table 1. Overview of the nuclear countries' panels.

\begin{tabular}{|c|c|c|c|c|}
\hline Country & Partners & Emergency phases & Scenarios & Main objectives/goal \\
\hline France & IRSN/CEPN & $\begin{array}{l}\text { Emergency and } \\
\text { transition phases }\end{array}$ & $\begin{array}{l}\text { Evacuation/relocation of } \\
\text { population and ban/ } \\
\text { restriction of the local } \\
\text { consumption and trade }\end{array}$ & $\begin{array}{l}\text { To identify and evaluate the } \\
\text { uncertainties of concern in the decision- } \\
\text { making process during the preparedness } \\
\text { phase and their interactions with } \\
\text { decision processes }\end{array}$ \\
\hline Spain & CIEMAT & Transition phase & $\begin{array}{l}\text { Contaminated inhabited } \\
\text { and agricultural areas }\end{array}$ & $\begin{array}{l}\text { To facilitate the engagement of relevant } \\
\text { stakeholders in the national post- } \\
\text { accident preparedness process, and to } \\
\text { assess their understanding of the critical } \\
\text { aspects and uncertainties that arise } \\
\text { during the transition phrase (to manage } \\
\text { the consequences of the accident and } \\
\text { plan the recovery) }\end{array}$ \\
\hline Belgium & SCK.CEN & Transition phase & Urban contamination & $\begin{array}{l}\text { To exchange views, experiences and } \\
\text { opinions related to the scientific and } \\
\text { societal uncertainties in the transition } \\
\text { phase }\end{array}$ \\
\hline Slovakia & VUJE & Transition phase & $\begin{array}{l}\text { Impact of evacuation/ } \\
\text { relocation of population } \\
\text { and urban area recovery }\end{array}$ & $\begin{array}{l}\text { To facilitate stakeholders' involvement } \\
\text { and to provide valuable input in the } \\
\text { process of decision making to improve } \\
\text { preparedness for and response during } \\
\text { the transition phase }\end{array}$ \\
\hline
\end{tabular}

Table 2. Overview of the non-nuclear countries' panels.

\begin{tabular}{|c|c|c|c|c|}
\hline Country & Partners & Emergency phases & Scenarios & Main objectives/goal \\
\hline Greece & EEAE & $\begin{array}{l}\text { Emergency response } \\
\text { and transition phase }\end{array}$ & $\begin{array}{l}\text { Contamination in food derived } \\
\text { from an accidental release } \\
\text { occurring in a neighbouring } \\
\text { country }\end{array}$ & $\begin{array}{l}\text { To trigger the active participation of the } \\
\text { stakeholders in formulating an effective } \\
\text { approach for dealing with the inherent } \\
\text { uncertainties in the management of a } \\
\text { nuclear emergency }\end{array}$ \\
\hline Norway & DSA & $\begin{array}{l}\text { Transition phase and } \\
\text { long-term recovery }\end{array}$ & $\begin{array}{l}\text { Agricultural scenario following } \\
\text { accident at floating Russian } \\
\text { nuclear power plant along the } \\
\text { Norwegian coast }\end{array}$ & $\begin{array}{l}\text { To discuss priorities and uncertainties } \\
\text { related to selection of actions and } \\
\text { strategies in the management of food } \\
\text { production in transition to long-term } \\
\text { recovery }\end{array}$ \\
\hline
\end{tabular}


most important issues to take into account when planning the transition phase of a nuclear emergency. Therefore, it was not used as a forecasting tool here, but some of the main characteristics of the Delphi tool (anonymity, iteration, feedback) have been maintained.

The study was carried out in two rounds. In the first round, the objective was to assess the importance of different issues, objectives, and challenges for recovery in order to prioritise them. A questionnaire was specifically designed covering the questions of interest (issues to be addressed during the transition phase/objectives of the recovery/challenges) and including a demographic section (with country and professional profile information, and the level of influence in the decision-making). The questionnaires were completed by 86 stakeholders from a sample of relevant stakeholders selected and invited through the WP4 partners from their own countries (Greece, Ireland, Slovak Republic, Spain, The Netherlands, Belgium and Norway).

The second round aimed at ranking the most relevant issues. For this purpose, the same topics as in the first questionnaire were included and the feedback from the aggregate results of the first round was provided to the participants. The participants were asked to distribute the potential efforts or resources (as a percentage) that they would devote to address the five items more relevant for them in each topic, in order to weight their relative importance into a recovery plan. Finally, the importance of different types of uncertainties pointed out in the panel discussions was assessed in order to rate them according to their relative importance. The same stakeholders as involved in the first round were invited. Fourteen Portuguese stakeholders joined this second round, but for methodological purposes, their responses could not be considered in the joint statistic. The final sample was $48 \%$ of the total participants in the first round. Figures 1 and 2 show the percentage distribution by participating country and by professional field, respectively. Public authorities (57\%) and researchers $(13 \%)$ were the most represented. The majority of participants $(78 \%)$ did show a keen interest in the discussion dealing with issues related to the transition phase. However, $45 \%$ also referred to their limited influence in the decisionmaking (stated as a mid-level influence).

Both questionnaires were translated to and distributed in the language/s of each country, or in English. Questionnaires were available online on the WP4 webpage and on paper for those who completed them out face to face. The first round of the Delphi study was conducted between June and October 2018 (and May 2019 in Norway), in order to be answered prior to the first panels' sessions. The second round was active between April and May 2019, before the second panel's meetings (in those countries that met twice).

The final responses were obtained by weighting equally all the experts' estimates from the second round and aggregating them. As there were not extreme values that could distort the means, the average was considered a good measure. The analysis was carried out using IBM SPSS 23.

\section{Main findings from the national panels}

A summary of the discussions, findings gathering the views of the stakeholders and conclusions obtained in the

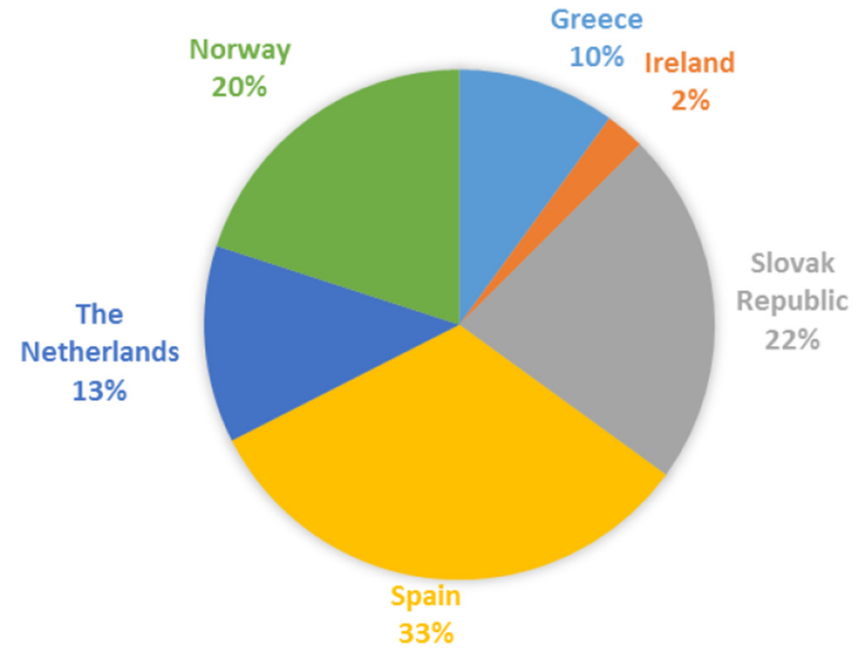

Fig. 1. Distribution of respondents to the second Delphi round by country $(N=41)$.

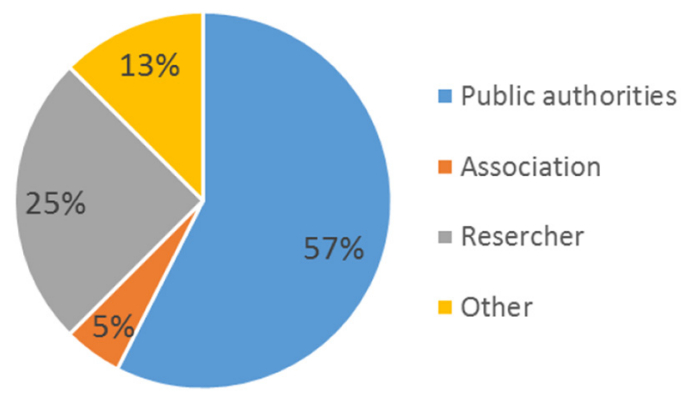

Fig. 2. Distribution by professional field of the sample of stakeholders participating in the second round $(N=41)$.

national panels has been included in a project report (Montero et al., 2019) and presented as national posters in the final workshop of the CONFIDENCE project (Duranova et al., 2020b). Here, the main findings and conclusions have been grouped into four decision specific issues that would be considered in the transition phase.

Regarding the management of consequences arising from decisions taken during the emergency (including evacuation and food restrictions), the panels recognised that the focus of the emergency phase is protecting the human health and that a proper radiological characterisation and knowledge of nonradiological hazards are needed. Uncertainties concerning the timing of decisions, public distrust and stigmatisation are the most challenging issues. Also, questions on the availability of resources and infrastructures necessary to ensure a wellmanaged evacuation, to carry out food restrictions, or to undertake measurement campaigns were highlighted. The need for wider information on the environmental and socioeconomic environment affected, to make better-supported decisions was raised. Stakeholders stressed that is necessary to assure trust among the population in policies developed at the national level and that communication with the affected population is crucial for this. It is important to check that decisions based on modelling data are consistent with the real situation when measurements results become available. 


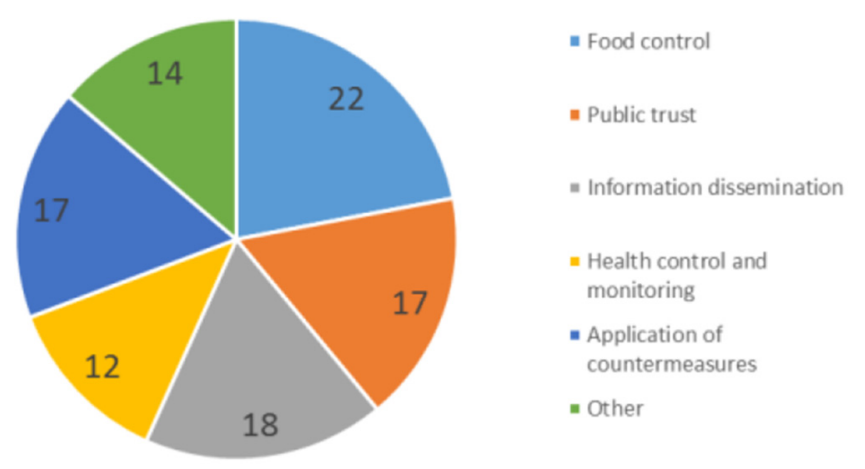

Fig. 3. Issues to be addressed during the transition phase: average percentage of resources allocated by respondents $(N=41)$.

Stakeholders indicated the importance of taking into account during the preparedness phase, the possible societal uncertainties, communication, the different issues and trust in early actions.

Additionally, it was highlighted that the precautionary principle should be used in the emergency phase by restrictions on food production and distribution in order to minimise the possible impact of the contamination during the transition phase. A measurement campaign would allow for a more precise estimation of the radiological impact, diminish the impact of the restrictions and refine the affected areas where remedial measures were needed.

Regarding the protective or remediation actions to implement in urban environments, the main issues were: returning to normal life as soon as possible, and dealing with the possible psychological problems and stigmatisation of people relocated. The panels stated that relocation should be minimised by combining with decontamination actions. The choice of the decontamination actions should be dependent on the level of contamination, taking care of "hot spots" in contaminated areas, and according to the typology and spatial distribution of houses and other buildings, the availability of infrastructures and location of green areas. The management of wastes arising from remedial actions is an additional challenge. The social cost is important in complex urban contamination situations and therefore, the strategies should be evidenceinformed, and with a constrained and temporary implementation, following a graded approach. In addition, it is important to keep a level of flexibility in post-accident management to have room for local decision-making and to involve the population in the decisions, giving freedom of choice and supporting self-reliance of the population.

In relation to protective or remediation actions for agricultural environments, the initial issue is the zoning of the affected areas. Zoning should be clearly set and enforced with ongoing monitoring/measurements programs and, in the first attempt, to identify vulnerable areas and affected agricultural systems. Local conditions and the temporal evolution of contamination and transfer through the food chain are challenges when applying recovery actions. The socio-economic consequences are at least as important as health effects, or even more so, in areas where the food and feed sector are the major industries. Management of agricultural production and husbandry during the first months strongly depends on the seasonal and weather conditions and characteristics of production systems. The strategies should include actions at different levels in the food production chain and should be implemented jointly and interrelated.

Regarding the protection and management of consumption and trade of food and other goods, the issues are mainly related to food control, including restrictions for consumption and trade. Essential elements for the stakeholders are food safety, availability of personnel and resources to undertake decontamination and management of waste resulting from contaminated products. In addition, knowledge is needed on the transfer of contamination through the food chain in order to plan effective strategies to protect the consumers. Monitoring programs and zoning systems, taking into account professionals' advice (e.g. producers and distributors), should be introduced in order to determine restrictions and to evaluate the success of the recovery actions. In the case of food restrictions, a compensation policy should be considered and discussed in advance with relevant stakeholders. The consumer response to the countermeasures taken, especially to what extent consumers will purchase goods produced from affected areas constitutes an important uncertainty. In that respect, communication will play a paramount role in the recovery strategy. The engagement of all actors involved in the food chain, including producers, processors, and distributors is crucial to implement the control measures and provide information to the consumers in order to gain their trust.

Finally, the panels recognised the need for preparedness for the post-accident recovery. It is essential to think broadly about the involvement of stakeholders representing the society in the decision-making processes. Establishing a network of stakeholder during the preparedness phase is key to ensuring the successful implementation of protective actions in the emergency, transition, and recovery phases. In addition, there is a need to make information on radioactivity available to people routinely. The recovery plans should address the minimisation of the radiological impact, as well as other impacts on the population as priority objectives, considering the effectiveness and feasibility of recovery actions in relation to the environmental, social and ethical factors influencing the decision-making process. Waste management also needs to be planned. During the transition phase, a consultation process involving all actors is needed for an effective response. This process requires the identification of key actors in advance, to be supported by predictive and monitoring tools previously adapted, tried and tested for national conditions, and by information on the environmental and socio-economic settings of the affected areas.

With respect to the criteria to assess and select the recovery actions, the stakeholder panels have indicated the following: effectiveness, feasibility, acceptance of countermeasures, radiological criteria, health consequences, side-effects, economical costs, availability of resources and infrastructures, availability of information supporting the decision-making process, trust, effects on the quality of life, public participation, psychosocial consequences, population perception, communication, ethical factors, waste amount and characteristics, among others.

In general, the interaction and engagement of stakeholders in the panel discussions was an enriching task for all stakeholders involved as well as a good introduction to the transition phase and the challenges of its management. In 
summary, the national panels' findings and outputs, with some slight distinctions between non-nuclear and nuclear countries, are:

- as time passes and depending on the distance from the contamination source, the social and economic issues would be probably more important than health issues, and the main goal will be to resume infrastructures and socioeconomic conditions that allow returning, as much as possible, to normal living conditions;

- the implementation of prompt food and animal-feed actions, both in terms of consumption restrictions (followed by gradual release based on actual measurements) or protective actions to reduce the transfer of radioactivity are understood by stakeholders to be essential to preserve the food and agriculture industry;

- it is relevant to involve various stakeholders in the decision-making process in the transition phase;

- the involvement of stakeholder in the preparedness phase is key in the decision-making process. The stakeholders consider that it is important and necessary to understand and be aware of the uncertainties, including the scientific ones, which could arise around decision-making. Most uncertainties can be considered and exercised in the preparedness phase;

- to have predictive and monitoring tools previously adapted, tried and tested, well-identified roles for the different public authorities and other bodies that should act, and well-established coordination, with the provision of adequate resources and infrastructures, are other elements to take into account during the preparedness phase and when planning the recovery strategies;

- there is a need to ensure that information related to the local situation is available at every stage of the decision-making process; local conditions are very important for both the implementation and effectiveness of a particular recovery action;

- communication plans should be ready in advanced; coherent and clear messages understandable by the population should be prepared in order to gain public trust in the implementation of a specific recovery strategy.

\section{Delphi findings}

At the end of the Delphi study, prioritisation of stakeholder preferences and a ranking of those uncertainties perceived as most important for the transition phase were obtained.

Figure 3 presents the main issues that the respondents consider need to be addressed during the transition phase and their relative importance in the recovery plans. According to respondents, $22 \%$ of the resources should be allocated to the "food control", following by "information dissemination/risk communication" with $18 \%$, and "public trust" and "application of countermeasures" with $17 \%$ each. Finally, "health control and monitoring" would receive $12 \%$ of efforts. The remaining $14 \%$ was allocated to other issues, mainly to "radioactivity surveillance" and "radiological characterization of contaminated areas".

With respect to the objectives of the recovery plan (Fig. 4), the minimisation of the social impacts was the most important

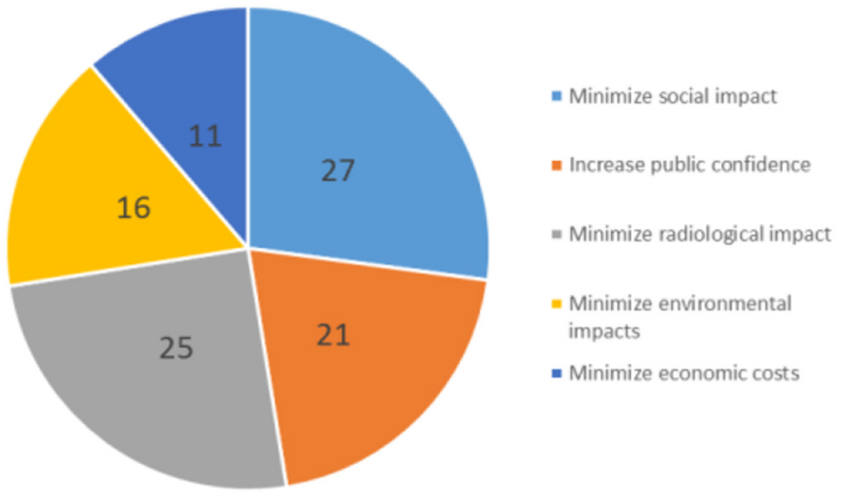

Fig. 4. Objectives of the recovery plan: percentage distribution $(N=41)$.

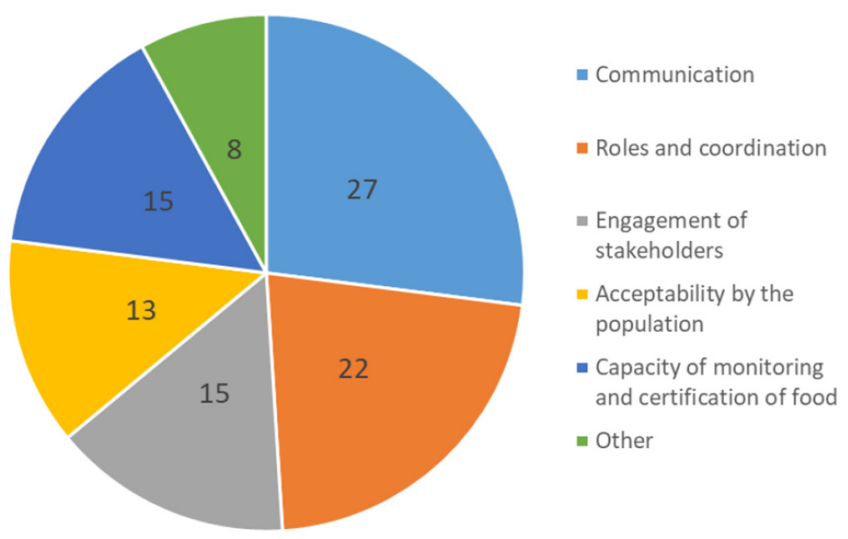

Fig. 5. Main challenges of the transition phase: percentage distribution of average resources allocated by the participants to the Delphi survey $(N=41)$.

objective (with the $27 \%$ of resources) very close to the minimisation of the radiological impact (25\%). Increase public confidence was perceived as a significant objective of the recovery plan, with $21 \%$ of the resources. Less importance is given to the minimisation of the environmental impact (16\%) and to the minimisation of economic costs $(11 \%)$.

Concerning the challenges of the transition phase, Figure 5 presents the most important ones according to respondents. "Communication with the public" (27\%) and "roles and coordination of the involved parties" (22\%) were perceived as the main challenges to deal with. "Monitoring and certification", as well as "engagement of stakeholders", follow with $15 \%$ of resources each. "Acceptability of the recovery strategy by the populations" was weighted with $13 \%$ of the efforts. The rest of $8 \%$ was divided among other challenges, mainly "the allocation of adequate resources".

Finally, regarding potential uncertainties to be addressed during the transition phase, all 29 uncertainties presented to the participants were considered highly important in the Delphi survey, ranging from 4.6 to 6.05 on a 7-point scale. In general, from the results, three groups of uncertainties can be derived, which mainly represent the views of public authorities and researchers: 
- high importance: those rated 6 or above: "How to ensure that foods found in homes and on the market do not generate panic or rejection?" "How to avoid stigmatization?" "What are the social consequences of the different strategies?";

- intermediate importance: those rated between 5 and 6 , such as "What to do with the waste?" "What is the acceptable level of contamination to lift or finish recovery actions?";

- medium-low importance: those rated 5 or below, such as: "Who will pay compensation?" "How to manage the maintenance and surveillance of restricted areas in the long term?".

Uncertainties highlighted as most important were related to food control and social aspects which were also identified as the main issues to be addressed. Thus, the most important aspects to manage during the transition are, at the same time, those with the most uncertainty.

Standard deviation ranges from 1.03 ("How to ensure that foods found in homes and on the market do not generate panic or rejection?") being the item that generated more agreement among participants (which emphasizes once again its importance); to 1.66 ("What to do with the waste?"), being the aspect that generated the least agreement among responders.

\section{Conclusions}

A structured process of participation combining scenariobased stakeholder discussion panels and structured transnational stakeholder (consultation) surveys (Delphi study) has been used to engage stakeholders in the preparation process for consequence management and post-accident recovery during the transition phase.

The participation of various stakeholder in the national panels was perceived as fruitful by the panellists themselves and conveyed their willingness to continue being involved, reporting the usefulness of the meetings in terms of knowing each other, better identification of roles and coordination and preparedness improvement.

Decision-oriented scenario-analysis clearly demonstrated added value and allowed us to identify, evaluate and optimise countermeasure strategies by involving stakeholders.

The nine panels organized under the CONFIDENCE WP4 allowed a broad and comprehensive view of many issues of interest to be obtained, including the stakeholder priorities associated with decision-making and the preparation of recovery plans during the transition phase of an emergency. Stakeholders were also confronted with uncertainties generated by ambiguity in the decision-making. Preferences and expectations of local and national stakeholders have been collected together with key criteria/attributes influencing the development and preference setting of the recovery strategies within the transition phase. From these results, recommendations to deal with and try to reduce such uncertainties were elaborated upon with the additional aim to identify gaps and further research needs (see Durand et al., 2020).

Using Delphi methodology has allowed the preparation of questions and issues to be used as a basis for panel discussions, to assess the relevance of the uncertainties identified and to select and prioritise the most relevant preferences and criteria resulting from the different panels so that they can be used in the decision-making tools developed by CONFIDENCE WP6 (see Müller et al., 2019, 2020; Duranova et al., 2020a).

Stakeholder engagement is essential in the preparedness, response and recovery phase of a nuclear or radiological emergency. Both panels and Delphi technique could be useful tools to facilitate constructive dialogue and consensus-building amongst diverse stakeholder groups. Specifically, the Delphi technique could be a valuable and efficient tool to obtain a quantitative assessment, if relevant stakeholders can be involved. In a complementary way, stakeholder panels can be used to consider the complexity of the relationships among the actors involved in the decision-making confronted with their different views and preferences. For both, it is necessary to maintain an active network of stakeholders to assay the process of national dialogue and to be prepared for possible future nuclear emergencies.

Acknowledgement. The work described in this paper was conducted within the CONFIDENCE project, which was part of the CONCERT project. The CONCERT project received funding from the Euratom Research and Training Programme (2014-2018) under grant agreement No. 662287.

Disclaimer (Art. 29.5 GA). This publication reflects only the author's view. Responsibility for the information and views expressed therein lies entirely with the authors. The European Commission is not responsible for any use that may be made of the information it contains.

\section{References}

Baudé S, Croüail P, Dewoghélaëre J, Duranova T, Hériard-Dubreuil G, Paiva I, Schneider T, Monteiro-Gil O, Madruga MJ, Reis M. 2019. Stakeholders' preferences and criteria for uncertainty management. CONCERT Deliverable D9.30. Available from https://www.concert-h2020.eu/en/Publications.

Bunting SW. 2010. Assessing the stakeholder Delphi for facilitating interactive participation and consensus building for sustainable aquaculture development. Soc. Nat. Resourc. 23(8): 758-775.

Campbell SM, Cantrill JA, Roberts D. 2000. Prescribing indicators for UK general practice: Delphi consultation study. BMJ 321 (7258): 425 .

Charron S et al. 2016. Overview of the PREPARE WP3: Management of contaminated goods in a post-accidental situation-Synthesis of European stakeholder' panels. Radioprotection 51(HS2): S83S91. https://doi.org/10.1051/radiopro/2016038.

Council Directive 2013/59/EURATOM, of 5 December. 2013. Laying down basic safety standards for protection against the dangers arising from exposure to ionising radiation. Available from https:// eur-lex.europa.eu/eli/dir/2013/59/oj.

Cousins C. 2019. Emergencies, ethics, and evolution, Nordic nuclear and radiation risk estimates - Advances and uncertainties. In: Joint $N K S$-R\&NKS-B Seminar, 15 January, 2019, Stockholm. Available from http://www.nks.org/download/seminar2019presentations/ cousins.pdf.

De Lhoneux A. 2017. Proposal for guidelines for the transposition and implementation of the provisions of Directive 2013/59/Euratom on EP\&R. Final report prepared by VNS for the European Commission under contract ENER/2015/NUCL/Si2.721507. Report VNS-TR-16-035 v1. 
ISBN 978-92-79-67896-7, https://doi.org/10.2833/270520. Available from https://publications.europa.eu/portal2012-portlet/html/ downloadHandler.jsp?identifier=4ae159eb-f455-11e8-998201 aa75ed71a1\&format $=$ PDF \&language $=$ en $\&$ productionSystem $=$ cellar.

Dubreuil GH, Baudé S, Lochard J, Ollagnon H, Liland A. 2010. The EURANOS cooperative framework for preparedness and management strategies of the long-term consequences of a radiological event. Radioprotection 45(5): S199-S213. https://doi.org/ 10.1051/radiopro/2010026.

Duranova T, van Asselt E, Müller T, Bohunova J, Twenhöfel CJW, Smetsers RCGM. 2020a. Decision making under uncertainties. MCDA Stakeholder workshops. Radioprotection 55(HS1). https://doi.org/10.1051/radiopro/2020032.

Duranova T, Bedwell P, Beresford NA, Bleher M, Gering F, Geertsema G, Hamburger T, Kaiser JC, Korsakissok I, Leadbetter SJ, Montero M, Müller T, Oughton D, Perko T, Raskob W, Tomas J, Turcanu C, de Vries H, Walsh L, Woda C. 2020b. CONFIDENCE dissemination meeting: Summary of the scenario-based workshop. Radioprotection 55(HS1). https://doi.org/10.1051/radiopro/2020009.

Durand V, Maître M, Croüail P, Schneider T, Sala R, Marques-Nunes P, Paiva I, Monteiro Gil O, Reis M, Hilliard C, Tafili V, Twenhöfel C, Van Asselt E, Trueba C, Montero M, Duranova T. 2020. Towards an improved decision-making process to better cope with uncertainties following a nuclear accident. Radioprotection 55 (HS1). https://doi.org/10.1051/radiopro/2020023.

Gallego E, Montero M. 2016. Experience in Spain with local-national fora for better post-accident preparedness. Radioprotection 51 (HS1): S31-S34. https://doi.org/10.1051/radiopro/2016008.

Gordon TJ. 1994. The Delphi method. Future Res. Methodol. 2(3): 1-30.

IAEA. 2018. Arrangements for the termination of a nuclear or radiological emergency. IAEA Safety Standards Series No. GSG11, IAEA, Vienna, 2018. Available from https://www.iaea.org/ publications/12269/arrangements-for-the-termination-of-a-nucle ar-or-radiological-emergency.

Liland A, Skuterud L. 2013. Lessons learned from the Chernobyl accident in Norway. In: Social and ethical aspects of radiation risk management. Radioactivity in the environment (D. Oughton, S.O. Hansson, Eds.) Volume 19, pp. 157-176. Elsevier Science. https://doi.org/10.1016/B978-0-08-045015-5.00010-1.

Liutsko L, Montero M, Trueba C, Sala R, Gallego E, Sarukhan A, Cardis E. 2019. Stakeholder participation in nuclear and radiological emergency preparedness and recovery in Spain: Benefits and challenges of working together. J. Radiat. Prot. Accepted manuscript online 8 November 2019. Available from https://doi.org/10.1088/1361-6498/ab55cd.

Lochard J, Schneider T, Ando R, Niwa O, Clement C, Lecomte JF, Tada JI. 2019. An overview of the dialogue meetings initiated by ICRP in Japan after the Fukushima accident. Radioprotection 54 (2): $87-101$.

Montero M, Trueba C, Sala R. 2018. Scenario-based stakeholder engagement. Guidelines for national discussions. Internal Technical Document CONFIDENCE-WP4/T4.2.1-R01 v1.0 Final.

Montero M, Trueba C, Sala R. 2019. Stakeholder engagement through scenario-based discussions panels. Compilation of national stakeholders' panel reports. CONCERT deliverable D9.22. Available from https://www.concert-h2020.eu/en/Publications.

Montero M, Sala R, Trueba C, Croüail P, Durand V, Gil OM, Maître M, Nunes PM, Paiva I, Reis M, Schneider T. 2020. Guidelines and recommendations for decision making during the transition phase. CONCERT deliverable D9.24. Available from https://www. concert-h2020.eu/en/Publications.

Müller T, Duranova T, van Asselt E, Twenhöfel CJW, French S, Andersson KG, Haywood S, Oughton D, Smith JQ, Turcanu C. 2019. Report from stakeholder panels and workshops related to the application of the methods and tools developed in ST9.1.6. CONCERT deliverable 9.36. Available from https://www.concerth2020.eu/en/Publications.

Müller T, Bai S, Raskob W. 2020. MCDA handling uncertainty. Radioprotection 55(HS1). https://doi.org/10.1051/radiopro/ 2020030.

Tetzlaff JM, Moher D, Chan AW. 2012. Developing a guideline for clinical trial protocol content: Delphi consensus survey. Trials 13 (1): 176 .

Cite this article as: Montero M, Sala R, Trueba C, García-Puerta B, Abelshausen B, Bohunova J, Croüail P, Durand V, Duranova T, Hilliard C, Maitre M, Mitrakos D, Monteiro Gil O, Nunes P, Paiva I, Reis M, Schneider T, Skuterud L, Smith V, Tafili V, Thørring H, Turcanu C, Twenhöfel C, Van Asselt E. 2020. Stakeholder involvement through national panels and surveys to address the issues and uncertainties arising in the preparedness and management of the transition phase. Radioprotection 55(HS1): S127-S134 